\title{
Mathematical Correction for Polyatomic Isobaric Spectral Interferences in Determination of Lanthanides by Inductively Coupled Plasma Mass Spectrometry
}

\author{
Narendra M. Raut, ${ }^{\mathrm{a}}$ Li-Shing Huang ${ }^{\mathrm{b}}$ ( 黃立心 ), \\ Suresh K. Aggarwal ${ }^{\mathrm{a}}$ and King-Chuen Lin ${ }^{\mathrm{b}}$ ( 林金全) \\ ${ }^{a}$ Fuel Chemistry Division, Bhabha Atomic Research Center, Trombay, Mumbai 400 085, India \\ ${ }^{\mathrm{b}}$ Department of Chemistry, National Taiwan University, and Institute of Atomic and Molecular Sciences, \\ Academia Sinica, Taipei 106, Taiwan, R.O.C.
}

\begin{abstract}
The determination of lanthanides by Inductively Coupled Plasma Mass Spectrometry (ICP-MS) is complicated by several spectral overlaps from $\mathrm{M}^{+}, \mathrm{MO}^{+}$or $\mathrm{MOH}^{+}$ions formed in the ICP. Especially, it is essential to avoid the spectral interferences from lighter lanthanide and $\mathrm{Ba}$ polyatomic ions on middle or heavier lanthanides. To tackle this problem, we have developed a mathematical correction method, which reduces all the spectral overlaps from oxide species of Pr, Nd, Ce and Sm over Gd, Tb, Dy and Ho, and Gd, Tb over Yb and $\mathrm{Lu}$. It can also successfully correct the oxide and hydroxide interference of Ba over Eu. The effectiveness of the proposed the mathematical correction scheme is demonstrated for the USGS Standard Rock samples AGV-1 and G-2. The results show that the experimental data obtained by applying the mathematical correction scheme for lanthanides is in good agreement with the reported values, using pneumatic and ultrasonic nebulisation methods, for their ICP-MS analysis.
\end{abstract}

Keywords: Lanthanides; ICP-MS.

\section{INTRODUCTION}

The importance of rare earth elements in view of their applications in different fields like geochemistry, nuclear fuel chemistry, environmental science, industries, etc. demands their determination from percentage level to ultra trace levels. There is an increasing use of lanthanides in different applications such as electronics, catalysts, and agriculture. ${ }^{1}$ As a consequence, lanthanides are released more into the environment and the currently investigated toxic properties of lanthanides demand their study in environmental science. ${ }^{2,3}$ The lanthanides represent a group of elements from La to Lu that show very similar physical and chemical properties. Knowledge of lanthanide distribution in rocks and minerals is very important from a geological point of view, especially in assessment of the origin of rock. ${ }^{4}$ The study of different chronological couples of lanthanides for their isotopic composition is useful in geochronology for age determination of rock. ${ }^{5}$
Inductively Coupled Plasma Mass Spectrometry (ICPMS) has become one of the most sensitive, rapid, accurate, and reliable trace multi-elemental measurement techniques. Despite the advantages, it has some disadvantages like spectral interference from isobaric ions, double charged ions, polyatomic ions like oxide and hydroxides, etc. Fortunately, for all lanthanides, at least one isotope is free from isobaric overlap due to atomic ions among themselves. The lanthanides are in the mass region from $139(\mathrm{La})$ to $175(\mathrm{Lu})$ that is almost free from matrix interference. Due to the high mass of lanthanides, they do not get interfered with by doubly charged species of other elements. However, the serious difficulty encountered in their determination by ICP-MS is the spectral overlap of oxides and hydrides species of lighter lanthanides over heavier lanthanides. For the sake of convenience, these elements are categorized in this paper into two subgroups as lighter lanthanides ( $\mathrm{La}$ to $\mathrm{Eu}$ ) and heavier lanthanides ( $\mathrm{Gd}$ to $\mathrm{Lu}$ ). The lanthanides are a group of elements that include some of the strongest oxide forming elements in ICP-MS. ${ }^{6}$

Dedicated to Professor Ching-Erh Lin on the Occasion of his $66^{\text {th }}$ Birthday and his Retirement from National Taiwan University

* Corresponding author. Fax:+886-2-23621483; E-mail: kclin@ccms.ntu.edu.tw 
These species occur at 16 to 18 a.m.u. above the parent ion and present a potential analytical problem for low abundant heavier lanthanides where they are being overlapped by the above species of lighter lanthanides. This interference problem can not be neglected when concentration of lighter lanthanides is much higher than that of heavier lanthanides. In addition, the most abundant element in many samples with lanthanides is $\mathrm{Ba}$ and its oxides and hydroxides which can interfere with some middle lanthanides, especially in the determination of Eu.

Many attempts have been made in the past to decrease oxide interferences. The oxides formed in the ICP-MS are caused by species that incorporate oxygen. As water is the major source of oxygen, desolvation techniques like ultrasonic nebuliser, ${ }^{7}$ membrane dryer, ${ }^{8}$ and cryogenic desolvation $^{9}$ were used to reduce oxide formation. A mixed gas plasma, such as $\mathrm{N}_{2}-\mathrm{Ar}^{10,11}$ or $\mathrm{H}_{2}-\mathrm{Ar}^{12}$ lowered $\mathrm{ArO}^{+}$substantially and oxide formation to some level. Optimization of sampler and skimmer orifice size helped reduce the yield of oxide signal to some extent. ${ }^{13}$ Although the amounts of these species can be minimized by optimizing instrumental parameters, it is not always possible to eliminate them completely.

A mathematical correction scheme is an alternative approach to correct for the oxide and hydroxide overlap problem and to eliminate almost complete error from these species. Spark Source Mass Spectrometry ${ }^{14}$ as well as ICP-MS ${ }^{15}$ has employed this approach in determination of lanthanides. However, some correction schemes encountered serious errors in determination of Eu by ICP-MS in the presence of a relatively high concentration of $\mathrm{Ba} .{ }^{16}$ Dulski has reported a mathematical correction equation that can correct only one interfering species at a time and may not be applied to unknown samples. ${ }^{17}$ Vaughan and Horlick have demonstrated the use of equation from Gauss elimination, ${ }^{18}$ but the method becomes complicated and elaborate for multiple spectral corrections.

In this paper, a simple and effective mathematical correction scheme is proposed to overcome the spectral interference from isobaric lanthanide ions, polyatomic oxides, or hydroxides ions in determination of lanthanides using ICP-MS under fixed optimized instrumental conditions. The data obtained from two nebulisation methods of pneumatic nebulizer and ultrasonic nebulizer, with high and low oxide yields, respectively, were processed for USGS certified rock samples (AGV-1 and G-2) using the above correction scheme. The results were found to be in good agreement with the certified values.

\section{EXPERIMENTAL}

\section{Apparatus}

A SCIEX ELAN 6000 ICP-MS (Perkin-Elmer, USA), as described elsewhere, ${ }^{19}$ was used for all data acquisition. It was run in sequential mode, peak hopping to masses of interest. A cross flow nebuliser and an ultrasonic nebuliser (U5000 AT, Cetac, USA) served as a sprayer for sample introduction. In an effort to avoid conductive coupling between the load coil and the plasma, both ends of the load coil were biased with high voltage of equal amplitude but opposite phase. The sampling depth between the sampler tip and top coil was fixed at $9 \mathrm{~mm}$ for all data acquisition. The coolant gas flow rate, the auxiliary gas flow rate, and the aerosol gas flow rate were fixed at $15.0,1.0$, and $0.95 \mathrm{~L} / \mathrm{min}$, respectively, throughout the experiment. The radio-frequency power was optimized to $1250 \mathrm{~W}$.

\section{Reagents}

De-ionized water (Millipore, USA) was used for the preparation of solutions. Indium (1000 ppm) was purchased from Merck. All the lanthanides (10 ppm each) and Ba (1000 ppm) standard solutions were purchased from High-Purity Standards, USA, and diluted to desired concentrations by $1 \%$ $\mathrm{HNO}_{3}$. Certified rock samples AGV-1 and G-2 containing lanthanides and $\mathrm{Ba}$ were obtained from the United States Geological Survey. Trace Pur grade $\mathrm{HNO}_{3}$ and Supra grade HF from Merck were used for digestion and dissolution of rock samples. Finally, all the solutions and samples were prepared in $1 \% \mathrm{HNO}_{3}$ for ICP-MS analysis. The heating temperature of ultrasonic nebuliser was optimized to $140{ }^{\circ} \mathrm{C}$ and the condenser temperature to $2{ }^{\circ} \mathrm{C}$.

The detailed digestion of the rock samples has been reported previously. ${ }^{20,21}$ Ultrasonication in conc. HF and conc. $\mathrm{HNO}_{3}$ medium was employed to dissolve AGV-1 for the extraction of lanthanides from solid silicate matrices. To extract the ultra-trace heavier lanthanides in G-2, the above digestion medium was modified to $1: 1 \mathrm{HCl}-\mathrm{HNO}_{3}$ in place of $\mathrm{HNO}_{3}$. The dissolved solutions were evaporated to dryness to remove the excess of fluorides and chlorides from $\mathrm{HF}$ and $\mathrm{HCl}$, respectively. They were further treated 2 to 3 times with conc. $\mathrm{HNO}_{3}$ to evaporate till dryness, followed by their dilution to the desired volume with $1 \% \mathrm{HNO}_{3}$ for ICP-QMS analysis. 


\section{MATHEMATICAL CORRECTION METHOD}

\section{Correction of isobaric spectral interference from oxide or hydroxide}

The correction scheme depends on the measurement of a single element standard for the oxide or hydroxide yield in $\%$ of each lanthanide and $\mathrm{Ba} .{ }^{\mathrm{M}} \mathrm{Ln}_{0}$ is one of the analyte isotopes of lanthanide with mass M. Assuming that an interfering element ${ }^{{ }^{\prime}} \mathrm{Ln}_{1}$ forms oxide or hydroxide with mass equal to $\mathrm{M}$, the error $\mathrm{E}$ in $\%$ from ${ }^{\mathrm{M}} \mathrm{Ln}_{1}$ can be estimated by the following equation

$$
E=e \cdot \frac{b}{a} \cdot \frac{x}{P} \cdot \frac{Q}{y} \cdot R
$$

The term e is \% yield of oxide or hydroxide of ${ }^{\mathrm{M}} \mathrm{Ln}_{1}$; a and $\mathrm{b}$ are the isotope abundances in $\%$ of ${ }^{\mathrm{M}} \mathrm{Ln}_{0}$ and ${ }^{\mathrm{M}} \mathrm{Ln}_{1}$ respectively. $x$ and $y$ are the signals of ${ }^{\mathrm{M}^{\prime \prime}} \mathrm{Ln}_{1}$ and ${ }^{\mathrm{M}^{*}} \mathrm{Ln}_{0}$, where ${ }^{\mathrm{M}^{*}} \mathrm{Ln}_{0}$ and ${ }^{\mathrm{M}} \mathrm{Ln}_{1}$ are the monitored isotopes of analyte and interfering lanthanide, respectively, and $\mathrm{M}^{\prime \prime} \neq \mathrm{M}^{\prime}$. P and $\mathrm{Q}$ are the isotope abundances of ${ }^{\mathrm{M}^{\prime \prime}} \mathrm{Ln}_{1}$ and ${ }^{\mathrm{M}^{*}} \mathrm{Ln}_{0}$, and $\mathrm{R}$ is the observed ratio of concentrations of $\mathrm{Ln}_{1}$ to $\mathrm{Ln}_{0}$ in a given sample.

The above equation calculates the error contribution by a single interfering element oxide or hydroxide. When more than one of such species are overlapping with the analyte, then the combined error can be calculated by adding the corresponding terms of an interfering element. The equation for ' $n$ ' number of such interfering oxides or hydroxides species can be modified as

$$
E=\frac{Q}{a \cdot y} \cdot\left(\sum_{i=1}^{n} e_{i} \cdot b_{i} \cdot x_{i} \cdot R_{i} / P_{i}\right)
$$

where $e_{i}, b_{i}, x_{i}, R_{i}$ and $P_{i}$ are the terms related to the interfering species for $\mathrm{i}=1$ to $\mathrm{n}$ and $\mathrm{Q}$, a, and $\mathrm{y}$ are the common terms of analyte. Q becomes equal to a, as $\mathrm{M}$ and $\mathrm{M}^{*}$ are chosen to be the same. Hence, equation (2) can be reduced to

$$
E=\frac{1}{y} \cdot\left(\sum_{i=1}^{n} e_{i} \cdot b_{i} \cdot x_{i} \cdot R_{i} / P_{i}\right)
$$

\section{Correction of isobaric interference among lanthanides}

As in equation (1), the error by lanthanide isobar depends on $\mathrm{a}^{\prime}$ and $\mathrm{b}^{\prime}$, the isotope abundance in $\%$ of analyte ${ }^{\mathrm{M}} \mathrm{Ln}_{0}$ and interfering element ${ }^{\mathrm{M}} \mathrm{Ln}_{2}$, respectively. $\mathrm{x}^{\prime}$ and $\mathrm{y}^{\prime}$ are the signals of ${ }^{\mathrm{M}^{\circ}} \mathrm{Ln}_{2}$ and ${ }^{\mathrm{M}^{*}} \mathrm{Ln}_{0}$ monitored (where, ${ }^{\mathrm{M}^{*}} \mathrm{Ln}_{0}$ is one of analyte element isotopes and ${ }^{\mathrm{M}^{\circ}} \mathrm{Ln}_{2}$ is one of interfering element isotopes, but $\mathrm{M}^{\circ} \neq \mathrm{M}$ ) and $\mathrm{P}^{\prime}$ and $\mathrm{Q}^{\prime}$ are the isotope abundances of ${ }^{\mathrm{M}^{\circ}} \mathrm{Ln}_{2}$ and ${ }^{\mathrm{M}^{*}} \mathrm{Ln}_{0}$, respectively. If $\mathrm{R}^{\prime}$ is the observed ratio of concentrations of interfering element to analyte element in the sample, then the \% error $\left(E^{\prime}\right)$ can be calculated by equation.

$$
E^{\prime}=\frac{b^{\prime}}{a^{\prime}} \cdot \frac{x^{\prime}}{P^{\prime}} \cdot \frac{Q^{\prime}}{y^{\prime}} \cdot R^{\prime} \cdot 100
$$

As $E^{\prime}$ is to be expressed in \%, 100 is used as a multiple factor. Again, $\mathrm{Q}^{\prime}$ and $\mathrm{a}^{\prime}$ are the same if $\mathrm{M}$ and $\mathrm{M}^{*}$ are chosen to be the same. Hence, the above equation can be reduced to

$$
E^{\prime}=\frac{1}{y^{\prime}} \cdot \frac{b^{\prime} \cdot x^{\prime}}{P^{\prime}} \cdot R^{\prime} \cdot 100
$$

For ' $\mathrm{m}$ ' number of such interfering isobars, the \% error becomes

$$
E^{\prime}=\frac{100}{y^{\prime}} \cdot\left(\sum_{j=1}^{m} b_{j}^{\prime} \cdot x_{j}^{\prime} \cdot R_{j}^{\prime} / P_{j}^{\prime}\right)
$$

Total correction from all types of isobaric interferences

Combining equations ( 3 ) and (6) as $\mathrm{y}=\mathrm{y}^{\prime}$ for an analyte element, we can estimate total error over it from any oxide or hydroxide species and isobaric interference among themselves by the following equation

$$
\begin{aligned}
E_{\text {total }}= & \frac{1}{y}\left[\left(\sum_{i=1}^{n} e_{i} \cdot b_{i} \cdot x_{i} \cdot R_{i} / P_{i}\right)\right. \\
& \left.+100\left(\sum_{j=1}^{m} b_{j}^{\prime} \cdot x_{j}^{\prime} \cdot R_{j}^{\prime} / P_{j}^{\prime}\right)\right]
\end{aligned}
$$

As mentioned before, $\mathrm{R}$ and $\mathrm{R}^{\prime}$ are the observed ratios of concentrations of interfering element to analyte element in a given unknown sample. As the signal of analyte element used in $\mathrm{R}$ and $\mathrm{R}^{\prime}$ is spectrally interfered with by an interfering element in the sample, the calculated \% error $\left(\mathrm{E}_{\text {total }}\right)$ using these $\mathrm{R}$ values would be incorrect. To correct it, the following equation obtained by iterative procedure should be used.

$$
E_{\text {corrected }}=100 E_{\text {total }} /\left(100-E_{\text {total }}\right)
$$

This correction scheme is applicable not only for oxide correction in lanthanides determination but also in several other elemental determinations to correct the polyatomic interferences.

\section{RESULTS AND DISCUSSION}

\section{Yield measurement of oxides and hydroxides}

Table 1 shows the different lanthanide isotopes from 
Table 1. Spectral interference with lanthanides

\begin{tabular}{|c|c|c|c|}
\hline Lanthanide & Mass & $\%$ Abundance & Interference \\
\hline \multirow[t]{2}{*}{$\mathrm{La}$} & 138 & 0.09 & $\mathrm{Ba}, \mathrm{Ce}$ \\
\hline & 139 & 99.91 & ---- \\
\hline \multirow[t]{4}{*}{$\mathrm{Ce}$} & 136 & 0.19 & $\mathrm{Ba}, \mathrm{Xe}$ \\
\hline & 138 & 0.25 & $\mathrm{La}, \mathrm{Ba}$ \\
\hline & 140 & 88.48 & ---- \\
\hline & 142 & 11.08 & $\mathrm{Nd}$ \\
\hline $\operatorname{Pr}$ & 141 & 100.00 & ---- \\
\hline \multirow[t]{7}{*}{$\mathrm{Nd}$} & 142 & 27.13 & $\mathrm{Ce}$ \\
\hline & 143 & 12.18 & ---- \\
\hline & 144 & 23.80 & $\mathrm{Sm}$ \\
\hline & 145 & 08.30 & ---- \\
\hline & 146 & 17.19 & $\mathrm{BaO}$ \\
\hline & 148 & 5.76 & $\mathrm{Sm}, \mathrm{BaO}$ \\
\hline & 150 & 5.64 & $\mathrm{Sm}, \mathrm{BaO}$ \\
\hline \multirow[t]{7}{*}{$\mathrm{Sm}$} & 144 & 3.10 & $\mathrm{Nd}$ \\
\hline & 147 & 15.00 & ---- \\
\hline & 148 & 11.30 & $\mathrm{Nd}, \mathrm{BaO}$ \\
\hline & 149 & 13.80 & ---- \\
\hline & 150 & 7.40 & $\mathrm{Nd}, \mathrm{BaO}$ \\
\hline & 152 & 26.70 & $\mathrm{Gd}, \mathrm{BaO}, \mathrm{CeO}$ \\
\hline & 154 & 22.70 & $\mathrm{Gd}, \mathrm{BaO}, \mathrm{LaO}, \mathrm{CeO}$ \\
\hline \multirow[t]{2}{*}{$\mathrm{Eu}$} & 151 & 47.80 & $\mathrm{BaO}$ \\
\hline & 153 & 52.20 & $\mathrm{BaO}$ \\
\hline \multirow[t]{7}{*}{ Gd } & 152 & 0.20 & $\mathrm{Sm}, \mathrm{BaO}, \mathrm{CeO}$ \\
\hline & 154 & 2.18 & $\mathrm{Sm}, \mathrm{BaO}, \mathrm{LaO}, \mathrm{CeO}$ \\
\hline & 155 & 14.80 & $\mathrm{BaO}, \mathrm{LaO}$ \\
\hline & 156 & 20.47 & $\mathrm{Dy}, \mathrm{LaO}, \mathrm{CeO}, \mathrm{BaO}$ \\
\hline & 157 & 15.65 & $\mathrm{CeO}, \mathrm{PrO}, \mathrm{LaO}$ \\
\hline & 158 & 24.84 & Dy, $\mathrm{CeO}, \mathrm{PrO}, \mathrm{NdO}$ \\
\hline & 160 & 21.86 & $\mathrm{Dy}, \mathrm{SmO}, \mathrm{NdO}, \mathrm{CeO}$ \\
\hline $\mathrm{Tb}$ & 159 & 100.00 & $\mathrm{NdO}, \mathrm{PrO}$ \\
\hline \multirow[t]{7}{*}{ Dy } & 156 & 0.06 & $\mathrm{Gd}, \mathrm{LaO}, \mathrm{CeO}, \mathrm{BaO}$ \\
\hline & 158 & 0.10 & $\mathrm{Gd}, \mathrm{CeO}, \mathrm{PrO}, \mathrm{NdO}$ \\
\hline & 160 & 2.34 & $\mathrm{Gd}, \mathrm{SmO}, \mathrm{NdO}, \mathrm{CeO}$ \\
\hline & 161 & 18.90 & $\mathrm{NdO}$ \\
\hline & 162 & 25.50 & $\mathrm{Er}, \mathrm{NdO}$ \\
\hline & 163 & 24.90 & $\mathrm{NdO}, \mathrm{SmO}$ \\
\hline & 164 & 28.20 & $\mathrm{Er}, \mathrm{SmO}, \mathrm{NdO}$ \\
\hline Ho & 165 & 100.00 & $\mathrm{SmO}$ \\
\hline \multirow[t]{6}{*}{$\mathrm{Er}$} & 162 & 0.14 & Dy, NdO \\
\hline & 164 & 1.61 & $\mathrm{Dy}, \mathrm{SmO}, \mathrm{NdO}$ \\
\hline & 166 & 33.60 & $\mathrm{SmO}, \mathrm{NdO}$ \\
\hline & 167 & 22.95 & $\mathrm{EuO}, \mathrm{SmO}$ \\
\hline & 168 & 26.80 & $\mathrm{Yb}, \mathrm{NdO}, \mathrm{GdO}, \mathrm{SmO}, \mathrm{EuO}$ \\
\hline & 170 & 14.90 & $\mathrm{Yb}, \mathrm{GdO}, \mathrm{EuO}, \mathrm{SmO}$ \\
\hline $\mathrm{Tm}$ & 169 & 100.00 & $\mathrm{EuO}$ \\
\hline \multirow[t]{7}{*}{$\mathrm{Yb}$} & 168 & 0.13 & $\mathrm{Er}, \mathrm{NdO}, \mathrm{GdO}, \mathrm{SmO}, \mathrm{EuO}$ \\
\hline & 170 & 3.05 & $\mathrm{Er}, \mathrm{GdO}, \mathrm{EuO}, \mathrm{SmO}$ \\
\hline & 171 & 14.30 & $\mathrm{EuO}, \mathrm{GdO}$ \\
\hline & 172 & 21.90 & DyO, SmO, GdO \\
\hline & 173 & 16.12 & $\mathrm{GdO}$ \\
\hline & 174 & 31.80 & Hf, DyO, GdO \\
\hline & 176 & 12.70 & Lu, Hf, GdO, TbO, DyO \\
\hline \multirow[t]{2}{*}{$\mathrm{Lu}$} & 175 & 97.41 & $\mathrm{TbO}$ \\
\hline & 176 & 2.59 & $\mathrm{Yb}, \mathrm{Hf}, \mathrm{GdO}, \mathrm{TbO}, \mathrm{DyO}$ \\
\hline
\end{tabular}

mass number $138(\mathrm{La})$ to $176(\mathrm{Lu})$, their natural abundances in $\%$, and the interferences over them in ICP-MS analysis. Owing to their high $\mathrm{M}-\mathrm{O}$ bond strength, the formation of $\mathrm{MO}^{+}$ ions is significant in ICP. Ba that is normally present in larger concentration in nature than in lanthanides forms oxide and hydroxide and gives rise to spectral overlap on Eu and Sm. Fortunately, at least one isotope of each lanthanide is free from atomic isobaric overlaps among themselves. Some lighter and all heavier lanthanide isotopes are overlapped either by oxides or hydroxides of lanthanides or Ba. Due to this, selection of a lanthanide isotope is very crucial for their ICPMS analysis. The lanthanide isotope to be analyzed should not be isobarically overlapped by other lanthanide isotopes; it should be less interfered with by oxides or hydroxide species; at the same time it should have reasonable natural abundance for sensitive detection. Keeping these points in mind, isotopes shown in Table 2 were chosen for determination of lanthanides. If the lanthanide forms an oxide species in ICP, it occurs at 16, 17 and 18 a.m.u. and in hydroxide species at 17,18 and 19 a.m.u. above it. Due to very low isotopic abundance of O-17 (0.038\%) and O-18 (0.2\%), interference from oxide species of these isotopes are almost negligible.

The $\%$ yield of oxide and hydroxide species was determined using a single element solution of lanthanide and $\mathrm{Ba}$ in the concentration range of 0.01 to $10 \mathrm{ppb}$. The yield of hydroxide species of lanthanides was found to be 10 times lower than that of oxides. Hence, contribution of an error from hydroxide species was neglected. ${ }^{22}$ The $\%$ yield of oxide species for all lanthanides using ultrasonic nebuliser was found to be

Table 2. Major spectral interference on selected lanthanide isotopes in their ICP-MS analysis

\begin{tabular}{lcrl}
\hline Lanthanide & Mass & \% Abundance & \multicolumn{1}{c}{ Interference } \\
\hline $\mathrm{La}$ & 139 & 99.91 & ---- \\
$\mathrm{Ce}$ & 140 & 88.48 & ---- \\
$\mathrm{Pr}$ & 141 & 100.00 & --- \\
$\mathrm{Nd}$ & 143 & 12.18 & --- \\
$\mathrm{Sm}$ & 147 & 15.00 & $\mathrm{Ba}^{130} \mathrm{O}^{16} \mathrm{H}$ \\
$\mathrm{Eu}$ & 151 & 47.80 & $\mathrm{Ba}^{135} \mathrm{O}^{16}, \mathrm{Ba}^{134} \mathrm{O}^{16} \mathrm{H}$ \\
$\mathrm{Gd}$ & 157 & 15.65 & $\mathrm{Pr}^{141} \mathrm{O}^{16}$ \\
& 158 & 24.84 & $\mathrm{Ce}^{142} \mathrm{O}^{16}, \mathrm{Nd}^{142} \mathrm{O}^{16}, \mathrm{Dy}-158$ \\
& 160 & 21.86 & $\mathrm{Sm}^{144} \mathrm{O}^{16}, \mathrm{Nd}^{144} \mathrm{O}^{16}, \mathrm{Dy}-160$ \\
$\mathrm{~Tb}$ & 159 & 100.00 & $\mathrm{Nd}^{143} \mathrm{O}^{16}$ \\
$\mathrm{Dy}$ & 163 & 24.90 & $\mathrm{Sm}^{147} \mathrm{O}^{16}$ \\
$\mathrm{Ho}$ & 165 & 100.00 & $\mathrm{Sm}^{149} \mathrm{O}^{16}$ \\
$\mathrm{Er}$ & 167 & 22.95 & $\mathrm{Eu}^{151} \mathrm{O}^{16}$ \\
$\mathrm{Tm}$ & 169 & 100.00 & $\mathrm{Eu}^{153} \mathrm{O}^{16}$ \\
$\mathrm{Yb}$ & 171 & 14.30 & $\mathrm{Gd}^{155} \mathrm{O}^{16}$ \\
$\mathrm{Lu}$ & 175 & 97.40 & $\mathrm{~Tb}^{159} \mathrm{O}^{16}$ \\
\hline
\end{tabular}


almost the same in the range of 0.1 to $10 \mathrm{ppb}$, as shown in Figs. $1 \& 2$. The \% oxide yield is even maintained below 0.1 $\mathrm{ppb}$ for most of the lanthanides like La, Ce, Pr, Tb, Dy, Ho, $\mathrm{Tm}, \mathrm{Lu}$, etc. that have more naturally abundant isotope. But it increases dramatically for less abundant isotopes of lanthanides like Nd, Sm, Gd, Er, Yb, etc. chosen for analysis. This is due to the contribution of background signals in low signals of oxide of less abundant lanthanides. The yield of oxide and hydroxide of $\mathrm{Ba}$ is almost the same (Fig. 3). Thus, the main interference is observed from oxide of lanthanides and, oxide and hydroxide of Ba with O-16.

Table 3 shows a comparison of \% yield of oxides of lanthanides using ultrasonic nebuliser and pneumatic nebuliser. The \% yield of oxides is reduced approximately by a factor of 3-5 with the use of ultrasonic nebuliser. With the observed oxide yield, ${ }^{143} \mathrm{NdO},{ }^{144} \mathrm{NdO},{ }^{155} \mathrm{GdO}$, and ${ }^{159} \mathrm{TbO}$ seriously

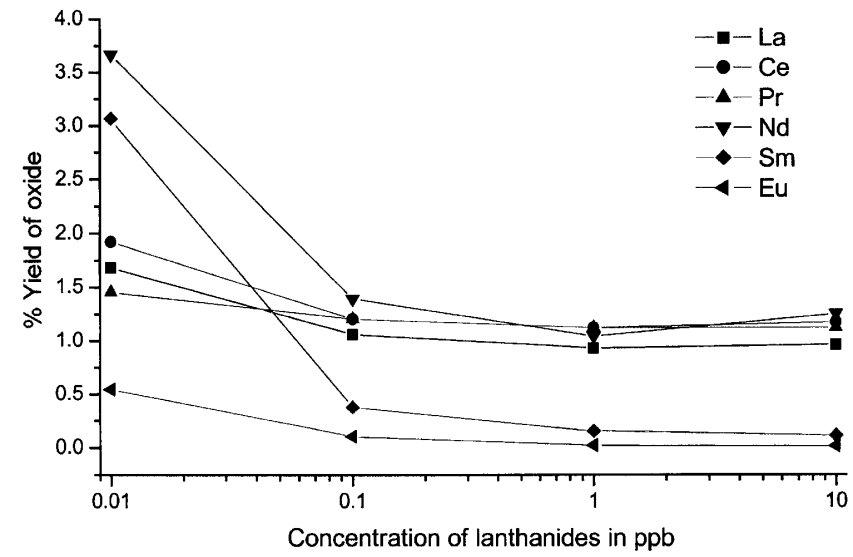

Fig. 1. \% oxide yield of lanthanides (La to Eu except for $\mathrm{Pm}$ ) with respect to their concentrations in the range 0.01 to $10 \mathrm{ppb}$.

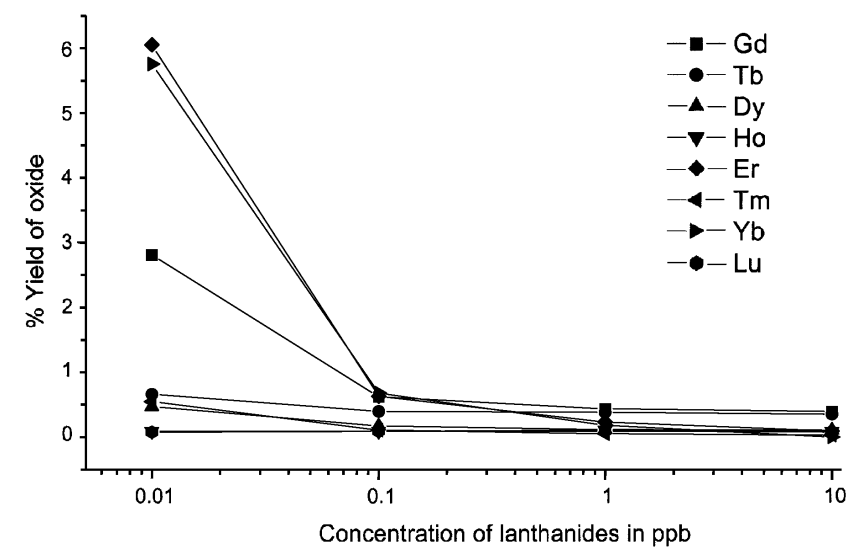

Fig. 2. \% oxide yield of lanthanides ( $\mathrm{Gd}$ to $\mathrm{Lu}$ ) with respect to their concentrations in the range 0.01 to $10 \mathrm{ppb}$.
Table 3. Comparison of $\%$ oxide yield of lanthanides using two different nebulisation methods

\begin{tabular}{lcc}
\hline Lanthanide & $\begin{array}{c}\text { Pneumatic nebuliser } \\
\text { LnO \% yield }( \pm 20 \%)\end{array}$ & $\begin{array}{c}\text { Ultrasonic nebuliser } \\
\text { LnO \% yield }( \pm 20 \%)\end{array}$ \\
\hline $\mathrm{La}$ & 1.95 & 0.70 \\
$\mathrm{Ce}$ & 2.32 & 0.92 \\
$\mathrm{Pr}$ & 2.34 & 0.80 \\
$\mathrm{Nd}$ & 2.30 & 0.72 \\
$\mathrm{Sm}$ & 0.30 & 0.06 \\
$\mathrm{Eu}$ & 0.03 & 0.0065 \\
$\mathrm{Gd}$ & 1.09 & 0.34 \\
$\mathrm{~Tb}$ & 1.07 & 0.29 \\
$\mathrm{Dy}$ & 0.43 & 0.097 \\
$\mathrm{Ho}$ & 0.39 & 0.079 \\
$\mathrm{Er}$ & 0.39 & 0.087 \\
$\mathrm{Tm}$ & 0.14 & 0.026 \\
$\mathrm{Yb}$ & 0.014 & 0.0027 \\
$\mathrm{Lu}$ & 0.30 & 0.06 \\
$\mathrm{Ba}$ & $0.0907^{\mathrm{a}}$ & $0.0237^{\mathrm{a}}$ \\
& $0.0426^{\mathrm{b}}$ & $0.0178^{\mathrm{b}}$ \\
\hline
\end{tabular}

${ }^{\mathrm{a}} \mathrm{BaO}$

${ }^{\mathrm{b}} \mathrm{BaOH}$

hamper the analysis of Tb-159, Gd-160, Yb-171 and Lu-175, respectively. ${ }^{135} \mathrm{BaO}$ and ${ }^{134} \mathrm{BaOH}$ also seriously overlap Eu151. To remove these interferences, we have applied the mathematical correction method developed in this work to correct multiple spectral errors in the analysis.

\section{Validation of mathematical correction method}

The validity of the developed mathematical correction scheme was done by analysis of reference rock samples (AGV-1 and G-2) by ICP-MS. The non-spectral interferences that often arise by matrix effect or due to instrumental fluctu-

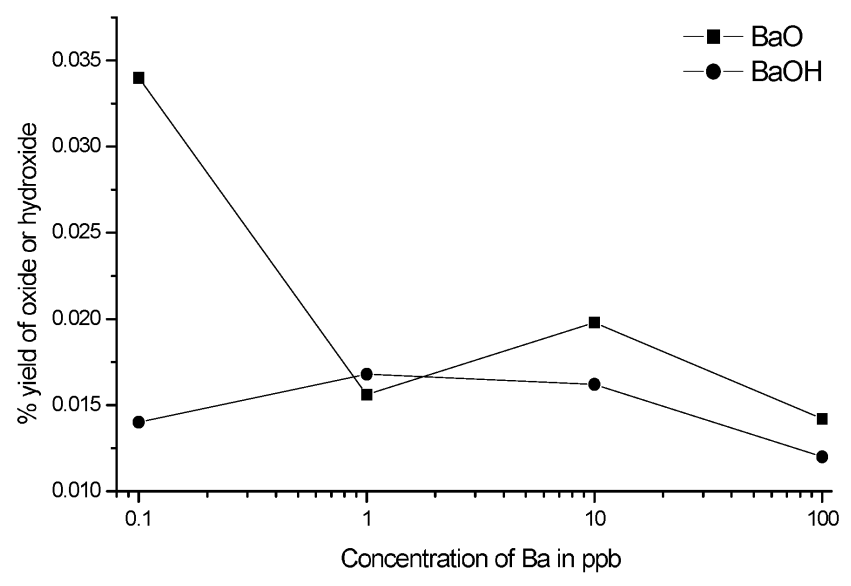

Fig. 3. \% oxide or hydroxide yield of Ba with respect to its concentration in the range 0.1 to $100 \mathrm{ppb}$. 
ations have been corrected using internal standard. Indium is a good element to be used as internal standard for analysis of natural material like rock samples because 1) it is seldom found at measurable concentration levels, 2) it has ionization potential close to that of lanthanides, and 3) it has two isotopes at $m / z 113$ and 115 that are relatively interference free and occur at abundances of 4.3 and $95.7 \%$, respectively. ${ }^{23}$ In-115 is a more suitable isotope as an internal standard because of its high natural abundance. It shows isobaric interference with Sn-115 (0.34\%) and ${ }^{99} \mathrm{Ru}^{16} \mathrm{O}$. Hence, both the rock samples (AGV-1 and G-2) were checked for Sn and Ru. The concentration of $\mathrm{Ru}$ in both the samples is below detection limits. Due to low natural abundance of Sn-115, its contribution to In signal will be less than $0.1 \%$ and hence can be neglected. The contribution of $\%$ error in the analysis of lanthanides was calculated from 1) the oxide yields of interfering elements, 2) lanthanide isobars, and 3) oxides and hydroxides yields of $\mathrm{Ba}$. The results are given in Tables 4 to 7 for AGV-1 and G-2 for lanthanides with and without applying mathematical correction using two nebulisation systems. In order to check the suitability of our mathematical correction scheme, the same data of lanthanides was corrected by different mathematical correction methods previously reported. ${ }^{17,19}$ These results obtained for AGV-1 and G-2 are also shown in Tables 4 to 7.

For La to $\mathrm{Nd}$, mathematical correction was not applied, since the selected isotopes of these elements for their determination are free from spectral overlaps. ${ }^{130} \mathrm{Ba}^{16} \mathrm{OH}$ overlaps $\mathrm{Sm}-147$. The natural abundance of Ba-130 is very low $(0.106 \%)$. Hence, the interference calculated from ${ }^{130} \mathrm{Ba}^{16} \mathrm{OH}$ is negligible. Similarly, $\mathrm{SmO}$ and EuO overlap Dy, Ho, Er and Tm. Since the oxide yields of Sm and Eu are very low, their interference can be neglected. Oxide formation of $\mathrm{La}$, $\mathrm{Ce}, \mathrm{Pr}, \mathrm{Nd}$ in lighter lanthanides and, $\mathrm{Gd}$ and $\mathrm{Tb}$ in heavier lanthanides, is significant. Hence, spectral overlaps from their oxides must be corrected. ${ }^{135} \mathrm{Ba}^{16} \mathrm{O}$ and ${ }^{134} \mathrm{Ba}^{16} \mathrm{OH}$ overlap Eu-151. Despite low natural abundances of Ba-134 (2.4\%) and $\mathrm{Ba}-135(6.6 \%)$, the concentration of $\mathrm{Ba}$ in the two rock samples (1230 ppmw in AGV-1 and 1880 ppmw in G-2) is about 3 orders of magnitude higher than that of $\mathrm{Eu}$, and the resultant interferences from $\mathrm{BaO}$ and $\mathrm{BaOH}$ over Eu are severe. The correction was applied to $\mathrm{Sm}, \mathrm{Eu}, \mathrm{Gd}, \mathrm{Tb}, \mathrm{Yb}$, and $\mathrm{Lu}$ analysis using pneumatic and ultrasonic nebulisers, separately. For most of the lanthanides, the corrected concentra-

Table 4. Lanthanides determination in AGV-1 in units of ppmw, using pneumatic nebuliser

\begin{tabular}{|c|c|c|c|c|c|c|}
\hline Ln & $\begin{array}{c}\text { USGS } \\
\text { recommended } \\
\text { concentration }^{\mathrm{a}, \mathrm{b}}\end{array}$ & $\begin{array}{c}\text { Reported } \\
\text { concentration }^{\mathrm{c}}\end{array}$ & $\begin{array}{l}\text { Uncorrected } \\
\text { concentration }^{\mathrm{d}}\end{array}$ & $\begin{array}{c}\text { Corrected } \\
\text { concentration }^{\mathrm{e}} \\
\text { This work }\end{array}$ & $\begin{array}{c}\text { Corrected } \\
\text { concentration }^{\mathrm{e}, \mathrm{f}}\end{array}$ & $\begin{array}{c}\text { Corrected } \\
\text { concentration }^{\mathrm{e}, \mathrm{g}}\end{array}$ \\
\hline $\mathrm{La}$ & $38(7.9)$ & $58(52.6)$ & $38.00(0.0)$ & $38.00(0.0)$ & $38.00(0.0)$ & $38.00(0.0)$ \\
\hline $\mathrm{Ce}$ & $67(7.5)$ & $70(4.5)$ & $69.19(3.3)$ & $69.19(3.3)$ & $69.19(3.3)$ & $69.19(3.3)$ \\
\hline $\operatorname{Pr}$ & $7.6(14.5)$ & $8.3(9.2)$ & $8.40(10.5)$ & $8.40(10.5)$ & $8.40(10.5)$ & $8.40(10.5)$ \\
\hline $\mathrm{Nd}$ & $33(9.1)$ & $31(6.1)$ & $30.82(6.6)$ & $30.82(6.6)$ & $30.82(6.6)$ & $30.82(6.6)$ \\
\hline $\mathrm{Sm}$ & $5.9(6.8)$ & $5.7(3.4)$ & $5.96(1.0)$ & $5.96(1.0)$ & $5.96(1.0)$ & $5.96(1.0)$ \\
\hline $\mathrm{Eu}$ & $1.6(6.1)$ & $1.7(3.7)$ & $1.74(8.8)$ & $1.60(0.0)$ & $1.68(5.0)$ & $1.61(0.6)$ \\
\hline $\mathrm{Gd}$ & $5.0(10.0)$ & $5.3(6.0)$ & $6.53(30.6)$ & $4.94(1.2)$ & $6.00(20.0)$ & $5.03(0.6)$ \\
\hline $\mathrm{Tb}$ & $0.7(14.3)$ & $0.7(0.0)$ & $0.77(10.0)$ & $0.68(2.9)$ & $0.73(4.3)$ & $0.68(2.86)$ \\
\hline Dy & $3.6(8.3)$ & $2.3(36.1)$ & $3.81(5.8)$ & $3.81(5.8)$ & $3.81(5.8)$ & $3.81(5.8)$ \\
\hline Но & $0.67(14.9)$ & $0.7(4.5)$ & $0.67(0.0)$ & $0.67(0.0)$ & $0.67(0.0)$ & $0.67(0.0)$ \\
\hline $\mathrm{Er}$ & $1.7(11.8)$ & $1.9(11.8)$ & $1.87(10.0)$ & $1.87(10.0)$ & $1.87(10.0)$ & $1.87(10.0)$ \\
\hline $\mathrm{Tm}$ & $0.34(38.2)^{*}$ & $0.26(23.5)$ & $0.26(23.5)$ & $0.26(23.5)$ & $0.26(23.5)$ & $0.26(23.5)$ \\
\hline $\mathrm{Yb}$ & $1.72(11.0)$ & $1.7(0.0)$ & $1.74(1.2)$ & $1.66(3.5)$ & $1.71(0.6)$ & $1.65(4.1)$ \\
\hline $\mathrm{Lu}$ & $0.27(11.1)$ & $0.23(14.8)$ & $0.28(3.7)$ & $0.27(0.0)$ & $0.28(3.7)$ & $0.27(0.0)$ \\
\hline
\end{tabular}

* Provisional value

a The parenthesized values indicate \% error in USGS recommendation.

${ }^{\mathrm{b}}$ Reference 24 .

${ }^{\mathrm{c}}$ Reference 25 .

${ }^{\mathrm{d}}$ The parenthesized values indicate \% error, determined by (Uncorrected concentration - USGS recommended concentration) $\times 100 /$ USGS recommended concentration.

${ }^{\mathrm{e}}$ The parenthesized values indicate $\%$ error, determined by (Corrected concentration - USGS recommended concentration) $\times 100 /$ USGS recommended concentration.

${ }^{\mathrm{f}}$ The corrected concentrations are based on the scheme reported in reference 17.

${ }^{g}$ The corrected concentrations are based on the scheme reported in reference 18 . 
Table 5. Lanthanides determination in AGV-1 in units of ppmw, using ultrasonic nebuliser

\begin{tabular}{|c|c|c|c|c|c|c|}
\hline $\mathrm{Ln}$ & $\begin{array}{c}\text { USGS } \\
\text { recommended } \\
\text { concentration }^{\mathrm{a}, \mathrm{b}}\end{array}$ & $\begin{array}{c}\text { Reported } \\
\text { concentration }^{\mathrm{c}}\end{array}$ & $\begin{array}{l}\text { Uncorrected } \\
\text { concentration }^{\mathrm{d}}\end{array}$ & $\begin{array}{c}\text { Corrected } \\
\text { concentration }^{\mathrm{e}} \\
\text { This work }\end{array}$ & $\begin{array}{c}\text { Corrected } \\
\text { concentration }^{\text {e,f }}\end{array}$ & $\begin{array}{c}\text { Corrected } \\
\text { concentration }^{\mathrm{e}, \mathrm{g}}\end{array}$ \\
\hline $\mathrm{La}$ & $38(7.9)$ & $58(52.6)$ & $38.69(1.8)$ & $38.69(1.8)$ & $38.69(1.8)$ & $38.69(1.8)$ \\
\hline $\mathrm{Ce}$ & $67(7.5)$ & $70(4.5)$ & $69.78(4.2)$ & $69.78(4.2)$ & $69.78(4.2)$ & $69.78(4.2)$ \\
\hline $\operatorname{Pr}$ & $7.6(14.5)$ & $8.3(9.2)$ & $8.42(10.8)$ & $8.42(10.8)$ & $8.42(10.8)$ & $8.42(10.8)$ \\
\hline $\mathrm{Nd}$ & $33(9.1)$ & $31(6.1)$ & $31.46(4.7)$ & $31.46(4.7)$ & $31.46(4.7)$ & $31.46(4.7)$ \\
\hline $\mathrm{Sm}$ & $5.9(6.8)$ & $5.7(3.4)$ & $5.81(1.5)$ & $5.81(1.5)$ & $5.81(1.5$ & $5.80(1.7)$ \\
\hline $\mathrm{Eu}$ & $1.6(6.1)$ & $1.7(3.7)$ & $1.68(5.0)$ & $1.64(2.5)$ & $1.67(4.4)$ & $1.65(3.1)$ \\
\hline $\mathrm{Gd}$ & $5.0(10.0)$ & $5.3(6.0)$ & $5.87(17.4)$ & $5.04(0.8)$ & $5.65(13.0)$ & $5.22(4.4)$ \\
\hline $\mathrm{Tb}$ & $0.7(14.3)$ & $0.7(0.0)$ & $0.71(1.4)$ & $0.67(4.3)$ & $0.69(1.4)$ & $0.67(4.3)$ \\
\hline Dy & $3.6(8.3)$ & $2.3(36.1)$ & $3.86(7.2)$ & $3.86(7.2)$ & $3.86(7.2)$ & $3.86(7.2)$ \\
\hline Ho & $0.67(14.9)$ & $0.7(4.5)$ & $0.71(5.9)$ & $0.71(5.9)$ & $0.71(5.9)$ & $0.71(5.9)$ \\
\hline $\mathrm{Er}$ & $1.7(11.8)$ & $1.9(11.8)$ & $1.96(15.3)$ & $1.96(15.3)$ & $1.96(15.3)$ & $1.96(15.3)$ \\
\hline $\mathrm{Tm}$ & $0.34(38.2)^{*}$ & $0.26(23.5)$ & $0.28(17.6)$ & $0.28(18.0)$ & $0.28(17.6)$ & $0.28(17.6)$ \\
\hline $\mathrm{Yb}$ & $1.72(11.0)$ & $1.7(0.0)$ & $1.71(0.6)$ & $1.69(1.7)$ & $1.71(0.6)$ & $1.69(1.7)$ \\
\hline $\mathrm{Lu}$ & $0.27(11.1)$ & $0.23(14.8)$ & $0.26(3.7)$ & $0.26(3.7)$ & $0.26(3.7)$ & $0.26(3.7)$ \\
\hline
\end{tabular}

* Provisional value

${ }^{\text {a }}$ The parenthesized values indicate \% error in USGS recommendation.

${ }^{\mathrm{b}}$ Reference 24.

${ }^{\mathrm{c}}$ Reference 25.

${ }^{\mathrm{d}}$ The parenthesized values indicate \% error, determined by (Uncorrected concentration - USGS recommended concentration) $\times 100 /$ USGS recommended concentration.

${ }^{\mathrm{e}}$ The parenthesized values indicate $\%$ error, determined by (Corrected concentration - USGS recommended concentration) $\times 100 /$ USGS recommended concentration.

${ }^{\mathrm{f}}$ The corrected concentrations are based on the scheme reported in reference 17.

${ }^{g}$ The corrected concentrations are based on the scheme reported in reference 18 .

Table 6. Lanthanides determination in G-2 in units of ppmw, using pneumatic nebuliser

\begin{tabular}{|c|c|c|c|c|c|c|}
\hline $\mathrm{Ln}$ & $\begin{array}{c}\text { USGS } \\
\text { recommended } \\
\text { concentration }^{\mathrm{a}, \mathrm{b}}\end{array}$ & $\begin{array}{c}\text { Reported } \\
\text { concentration }^{\mathrm{c}}\end{array}$ & $\begin{array}{l}\text { Uncorrected } \\
\text { concentration }^{\mathrm{d}}\end{array}$ & $\begin{array}{c}\text { Corrected } \\
\text { concentration }^{\mathrm{e}} \\
\text { This work }\end{array}$ & $\begin{array}{c}\text { Corrected } \\
\text { concentration }^{\mathrm{e}, \mathrm{f}}\end{array}$ & $\begin{array}{c}\text { Corrected } \\
\text { concentration }\end{array}$ \\
\hline $\mathrm{La}$ & $89(9.0)$ & $92(3.4)$ & $91.22(2.5)$ & $91.22(2.5)$ & $91.22(2.5)$ & $91.22(2.5)$ \\
\hline $\mathrm{Ce}$ & $160(6.3)$ & $164(2.5)$ & $166.60(4.1)$ & $166.60(4.1)$ & $166.60(4.1)$ & $166.60(4.1)$ \\
\hline $\operatorname{Pr}$ & $18(11.1)$ & $17(5.6)$ & $17.35(3.6)$ & $17.35(3.6)$ & $17.35(3.6)$ & $17.35(3.6)$ \\
\hline $\mathrm{Nd}$ & $55(10.9)$ & $51(7.3)$ & $56.29(2.4)$ & $56.29(2.4)$ & $56.29(2.4)$ & $56.29(2.4)$ \\
\hline $\mathrm{Sm}$ & $7.2(9.7)$ & $7.2(0.0)$ & $7.68(6.7)$ & $7.68(6.7)$ & $7.68(6.7)$ & $7.68(6.7)$ \\
\hline $\mathrm{Eu}$ & $1.4(8.6)$ & $1.4(0.0)$ & $1.75(25.0)$ & $1.48(5.7)$ & $1.64(17.1)$ & $1.46(4.3)$ \\
\hline Gd & $4.3(18.6)$ & $5.1(18.6)$ & $6.21(44.4)$ & $3.79(11.9)$ & $5.28(22.8)$ & $5.27(22.6)$ \\
\hline $\mathrm{Tb}$ & $0.48(16.7)$ & $0.56(16.7)$ & $0.71(47.9)$ & $0.49(2.1)$ & $0.62(29.2)$ & $0.49(2.1)$ \\
\hline Dy & $2.4(12.5)$ & $2.4(0.0)$ & $2.27(5.4)$ & $2.27(5.4)$ & $2.27(5.4)$ & $2.27(5.4)$ \\
\hline Ho & $0.4(15.0)$ & $0.37(7.5)$ & $0.36(10.0)$ & $0.36(10.0)$ & $0.36(10.0)$ & $0.36(10.0)$ \\
\hline $\mathrm{Er}$ & $0.92(19.6)$ & $0.91(1.1)$ & $0.80(13.0)$ & $0.80(13.0)$ & $0.80(13.0)$ & $0.80(13.0)$ \\
\hline $\mathrm{Tm}$ & $0.18(44.4)^{*}$ & $0.13(27.8)$ & $0.11(38.9)$ & $0.11(38.9)$ & $0.11(38.9)$ & $0.11(38.9)$ \\
\hline $\mathrm{Yb}$ & $0.8(21.3)$ & $0.52(35.0)$ & $0.63(21.3)$ & $0.59(26.3)$ & $0.61(23.8)$ & $0.51(36.3)$ \\
\hline $\mathrm{Lu}$ & $0.11(18.2)$ & $0.08(27.3)$ & $0.08(27.3)$ & $0.08(27.3)$ & $0.08(27.3)$ & $0.07(36.4)$ \\
\hline
\end{tabular}

* Provisional value

${ }^{a}$ The parenthesized values indicate \% error in USGS recommendation.

${ }^{\mathrm{b}}$ Reference 24.

${ }^{\mathrm{c}}$ Reference 25 .

${ }^{\mathrm{d}}$ The parenthesized values indicate \% error, determined by (Uncorrected concentration - USGS recommended concentration) $\times 100 /$ USGS recommended concentration.

${ }^{\mathrm{e}}$ The parenthesized values indicate $\%$ error, determined by (Corrected concentration - USGS recommended concentration) $\times 100 /$ USGS recommended concentration.

${ }^{\mathrm{f}}$ The corrected concentrations are based on the scheme reported in reference 17.

${ }^{\mathrm{g}}$ The corrected concentrations are based on the scheme reported in reference 18 . 
Table 7. Lanthanides determination in G-2 in units of ppmw, using ultrasonic nebuliser

\begin{tabular}{|c|c|c|c|c|c|c|}
\hline Ln & $\begin{array}{c}\text { USGS } \\
\text { recommended } \\
\text { concentration }^{\mathrm{a}, \mathrm{b}}\end{array}$ & $\begin{array}{c}\text { Reported } \\
\text { concentration }^{\mathrm{c}}\end{array}$ & $\begin{array}{l}\text { Uncorrected } \\
\text { concentration }^{\mathrm{d}}\end{array}$ & $\begin{array}{c}\text { Corrected } \\
\text { concentration }^{\mathrm{e}} \\
\text { This work }\end{array}$ & $\begin{array}{l}\text { Corrected } \\
\text { concentration }^{\mathrm{e}, \mathrm{f}}\end{array}$ & $\begin{array}{l}\text { Corrected } \\
\text { concentration, }\end{array}$ \\
\hline $\mathrm{La}$ & $89(9.0)$ & $92(3.4)$ & $97.22(9.2)$ & $97.22(9.2)$ & $97.22(9.2)$ & $97.22(9.2)$ \\
\hline $\mathrm{Ce}$ & $160(6.3)$ & $164(2.5)$ & $175.9(9.9)$ & $175.9(9.9)$ & $175.9(9.9)$ & $175.9(9.9)$ \\
\hline $\operatorname{Pr}$ & $18(11.1)$ & $17(5.6)$ & $16.93(5.9)$ & $16.93(5.9)$ & $16.93(5.9)$ & $16.93(5.9)$ \\
\hline $\mathrm{Nd}$ & $55(10.9)$ & $51(7.3)$ & $53.14(3.4)$ & $53.14(3.4)$ & $53.14(3.4)$ & $53.14(3.4)$ \\
\hline $\mathrm{Sm}$ & $7.2(9.7)$ & $7.2(0.0)$ & $7.24(0.6)$ & $7.24(0.6)$ & $7.24(0.6)$ & $7.24(0.6)$ \\
\hline $\mathrm{Eu}$ & $1.4(8.6)$ & $1.4(0.0)$ & $1.38(1.4)$ & $1.35(3.6)$ & $1.37(2.1)$ & $1.34(4.3)$ \\
\hline Gd & $4.3(18.6)$ & $5.1(18.6)$ & $5.45(26.7)$ & $4.19(2.6)$ & $4.99(16.0)$ & $4.32(0.5)$ \\
\hline $\mathrm{Tb}$ & $0.48(16.7)$ & $0.56(16.7)$ & $0.54(12.5)$ & $0.43(10.4)$ & $0.50(4.2)$ & $0.43(10.4)$ \\
\hline Dy & $2.4(12.5)$ & $2.4(0.0)$ & $2.35(2.1)$ & $2.35(2.1)$ & $2.35(2.1)$ & $2.35(2.1)$ \\
\hline Ho & $0.4(15.0)$ & $0.37(7.5)$ & $0.38(5.0)$ & $0.38(5.0)$ & $0.38(5.0)$ & $0.38(5.0)$ \\
\hline $\mathrm{Er}$ & $0.92(19.6)$ & $0.91(1.1)$ & $0.88(4.4)$ & $0.88(4.4)$ & $0.88(4.4)$ & $0.88(4.4)$ \\
\hline $\mathrm{Tm}$ & $0.18(44.4)^{*}$ & $0.13(27.8)$ & $0.12(33.3)$ & $0.12(33.3)$ & $0.12(33.3)$ & $0.12(33.3)$ \\
\hline $\mathrm{Yb}$ & $0.8(21.3)$ & $0.52(35.0)$ & $0.62(22.5)$ & $0.59(26.3)$ & $0.62(22.5)$ & $0.60(25.0)$ \\
\hline $\mathrm{Lu}$ & $0.11(18.2)$ & $0.08(27.3)$ & $0.08(27.3)$ & $0.08(27.3)$ & $0.08(27.3)$ & $0.08(27.3)$ \\
\hline \multicolumn{7}{|c|}{ Provisional value } \\
\hline \multicolumn{7}{|c|}{ a The parenthesized values indicate \% error in USGS recommendation. } \\
\hline \multicolumn{7}{|c|}{${ }^{\mathrm{b}}$ Reference 24.} \\
\hline \multicolumn{7}{|c|}{${ }^{\mathrm{c}}$ Reference 25.} \\
\hline \multicolumn{7}{|c|}{$\begin{array}{l}\mathrm{d} \text { The parenthesized values indicate } \% \text { error, determined by (Uncorrected concentration }- \text { USGS } \\
\text { recommended concentration) } \times 100 / \text { USGS recommended concentration. }\end{array}$} \\
\hline \multicolumn{7}{|c|}{$\begin{array}{l}\text { e The parenthesized values indicate } \% \text { error, determined by (Corrected concentration }- \text { USGS recommended } \\
\text { concentration) } \times 100 / \text { USGS recommended concentration. }\end{array}$} \\
\hline \multicolumn{7}{|c|}{${ }^{\mathrm{f}}$ The corrected concentrations are based on the scheme reported in reference 17 . } \\
\hline
\end{tabular}

tion values are closer to the certified values (Tables 4 to 7). For instance, the mathematical correction reduced error from 9 to $0 \%$ for $\mathrm{Eu}, 31$ to $1 \%$ for $\mathrm{Gd}, 10$ to $3 \%$ for $\mathrm{Tb}$, etc. in AGV-1 analysis using pneumatic nebuliser. Similarly, in G-2 analysis, the error was reduced from 25 to $6 \%$ for $\mathrm{Eu}, 44$ to $12 \%$ for $\mathrm{Gd}$ and 48 to $2 \%$ for $\mathrm{Tb}$. The $\%$ error in their determination was substantially reduced after the correction in both of the samples AGV-1 and G-2. However, one should note that when the uncorrected values are less than the certified values (Tables 5-7) such as for Yb, the corrected value shows slightly more error than the uncorrected.

The use of highly efficient ultrasonic nebulisation limits the oxide formation and hence the spectral overlaps. On comparing the uncorrected concentrations of $\mathrm{Sm}, \mathrm{Eu}, \mathrm{Gd}, \mathrm{Tb}$, $\mathrm{Yb}$, and $\mathrm{Lu}$ in both AGV-1 and G-2, we found that the results obtained by the ultrasonic nebulisation generally yield less \% error in their determination, except for Sm in AGV-1 and $\mathrm{Yb}$ and $\mathrm{Lu}$ in G-2, than those by the pneumatic nebulisation. Nevertheless, the ultrasonic nebulisation doesn't necessarily lead to less \% error after mathematical correction.

As listed in Tables 4-7, the corrected values for most of the lanthanides by our correction scheme turn out to be as ac- curate as those by Vaughan and Horlick, ${ }^{18}$ but more accurate than those by Dulski. ${ }^{17}$ Mathematical correction by Gauss elimination method reported by Vaughan and Horlick is better for single polyatomic correction. For multiple polyatomic corrections, the method becomes more elaborate and complicated. The corrected values by Dulski's method, which involves a factor of 0.33 in the correction scheme, appear to be larger than ours for almost each element considered. The correction equation ${ }^{17}$ may not be useful with unknown samples. The values obtained for heavier lanthanides such as Tm, Yb, and Lu in our work are lower in G-2 analysis than those compiled by Govindaraju for USGS certification. ${ }^{24}$ The same trend was observed by Aggarwal et al. ${ }^{25}$

\section{CONCLUSION}

Application of mathematical correction eliminates the spectral interference from oxide ions of lighter lanthanides and $\mathrm{Ba}$ over middle and heavier lanthanides. A good agreement was observed between the results obtained and the reported values for all the lanthanides in USGS rock samples 
AGV-1 and G-2. The developed mathematical correction equation provides a simple method for estimation of interference in any unknown sample and also facilitates the choice of a suitable isotope for its determination in a given sample. The correction scheme is necessary while using a pneumatic nebuliser, but becomes less significant, except for Eu and $\mathrm{Gd}$ in AGV-1 and Gd in G-2, with the use of ultrasonic nebuliser.

\section{ACKNOWLEDGEMENTS}

This work is financially supported by the National Science Council of Taiwan, Republic of China, under contract no. NSC 93-2113-M-002-028. N. M. R. is thankful to the Institute of Atomic and Molecular Sciences, Academia Sinica, for providing Ph.D. fellowship and research facilities during the collaboration.

Received December 10, 2004.

\section{REFERENCES}

1. Liang, L.; D'Haese, P. C.; Lamberts, L. V.; van de Vyver, F. L.; De Broe, E. Anal. Chem. 1991, 63, 423.

2. Prohaska, T.; Hann, S.; Latkoczy, C.; Stingeder, G. J. Anal. At. Spectrom. 1999, 14, 1.

3. Inagaki, K.; Haraguchi, H. Analyst 2000, 125, 191.

4. Gunter, F. Principles of Isotope Geology; $2^{\text {nd }} \mathrm{ed}$, John Wiley: New York, 1986.

5. Spedding, F. H.; Daan, A. H. The Rare Earths; John Wiley:
New York, 1961.

6. Douglas, D. J.; French, J. B. Spectrochim. Acta, Part B 1986, 41, 197.

7. Halicz, L.; Segal, I.; Yoffe, O. J. Anal. At. Spectrom. 1999, $14,1579$.

8. Tao, H.; Miyazaki, A. J. Anal. At. Spectrom. 1995, 10, 1.

9. Pin, C.; Telouk, P.; Imbert, J. L. J. Anal. At. Spectrom. 1995, 10, 93.

10. Lam, J. W. H.; Horlick, G. Spectrochim. Acta, Part B 1990, 45, 1313.

11. Craig, J. M.; Beauchemin, D. J. Anal. At. Spectrom. 1992, 7 , 937.

12. Louie, H.; Soo, S. Y. P. J. Anal. At. Spectrom. 1992, 7, 557.

13. Vaughan, M. A.; Horlick, G. Spectrochim. Acta, Part B 1990, 45, 1289.

14. Bacon, J. R.; Ure, A. M. Anal. Chim. Acta 1979, 105, 163.

15. Van Veen, E. H.; Bosch, S.; De Loos-Vollebregt, M. T. C. Spectrochim. Acta, Part B 1994, 49, 1347.

16. Cao, X.; Yin, M.; Wang, X. Spectrochim. Acta, Part B 2001 , 56, 431.

17. Dulski, P. Fresenius' Z. Anal. Chem. 1994, 350, 194.

18. Vaughan, M. A.; Horlick, G. Appl. Spectrosc. 1990, 44, 587.

19. Ke, S. H.; Huang, L. S.; Huang, J. S.; Lin, K. C. Appl. Spectrosc. 2001, 55, 604.

20. Raut, N. M.; Huang, L. S.; Aggarwal, S. K.; Lin, K. C. Spectrochim. Acta, Part B 2003, 58, 809.

21. Raut, N. M.; Huang, L. S.; Lin, K. C.; Aggarwal, S. K. Anal. Chim. Acta 2005, 530, 91.

22. Jarvis, K. E. J. Anal. At. Spectrom. 1989, 4, 563.

23. Montaser, A.; Golightly, D. W. Inductively Coupled Plasmas in Analytical Atomic Spectrometry; $2^{\text {nd }}$ ed, VCH: New York, 1992.

24. Govindaraju, K. Geostand. Newslett. 1989, 13, 1.

25. Aggarwal, J. K.; Shabani, M. B.; Palmer, M. R.; Vala Ragnarsdottir, K. Anal. Chem. 1996, 68, 4418. 